\title{
ARTIGOS
}

\section{O CONTRATUALISMO COMO MÉTODO: POLÍTICA, DIREITO E NEOCONTRATUALISMO}

J. R. N. Chiappin

\author{
Carolina Leister
}

\begin{abstract}
RESUMO
O objetivo deste artigo é apresentar o contratualismo como método e como o resultado de uma sistematização de outros métodos de construção do conhecimento. Enquanto o contratualismo clássico tem como paradigmas os modelos, geométrico e mecânico, da Física de Galileu e de Descartes - em particular, o modelo de escolha racional com Descartes -, o contratualismo rawlsiano tem como paradigma alguns modelos da microeconomia - em particular, o modelo de equilíbrio geral. O método contratualista tem como projeto a transformação, no século XVII, da política e do Direito em uma disciplina científica, assumindo que, no século XVII: (i) o modelo do conhecimento é o modelo geométrico e o conhecimento é conhecimento certo; (ii) o modelo de indivíduo admite-o como racional e auto-interessado; (iii) há uma teoria racional da ação e decisão humana. Portanto, para viabilizar o projeto de transformar a política e o Direito em ciência, o contratualismo é aqui interpretado não substantivamente, mas instrumentalmente, como método para acessar os fundamentos do mundo político. O método contratualista persegue uma combinação do modelo científico do conhecimento das causas eficientes e de suas relações aos efeitos, com o modelo de conhecimento das causas finais como estudo dos fins ou das características funcionais das coisas. Para interpretarmos o contratualismo como método, admitimos o novo modelo da relação entre conhecimento e tecnologia elaborado pela ciência moderna, que sustenta que o conhecimento da natureza é um conhecimento de conquista e domínio capaz de produzir mecanismos tecnológicos de intervenção na natureza com o objetivo de, conhecendo e manipulando as causas, obter os efeitos desejados.
\end{abstract}

PALAVRAS-CHAVE: método contratualista clássico; política e Direito como ciência; modelo geométrico; modelo de escolha racional; método de solução de problemas.

\section{INTRODUÇÃO}

Este artigo faz parte de um projeto de pesquisa relativo à reconstrução racional do programa de pesquisa da Política e do Direito como ciência, i.e., da Política e do Direito como disciplinas autônomas. Esse programa é considerado como um subprograma do programa racionalista, sua matriz epistemológica encetada no século XVII com Descartes, que possui seu método próprio para fazer de uma área de conhecimento uma disciplina científica. Esse método redefine a relação entre ciência e tecnologia, sustentando a ciência como conhecimento capaz de permitir ao homem intervir e controlar a natureza. O problema fundamental do programa da Política e do Direito como ciência é aquele de estabelecer as condições de surgimento e estabilidade da cooperação (CHIAPPIN \& OLIVEIRA, 1999) e tem como estratégias de solução os subprogramas contratualista e utilitarista (LEISTER, 2005). O subprograma contratualista desenvolveu como solução teórica e tecnológica ao problema da cooperação tanto a explicação e justificação teórica quanto a construção de tecnologias institucionais, as concepções do Estado de Direito e do indivíduo como pessoa. O subprograma utilitarista desenvolveu também sua própria versão de solução ao problema acima, o Estado Democrático de Direito e o Estado Social e Democrático de Direito com a concepção do indivíduo como cidadão. Enquanto solução tecnológica, o Estado dos utilitaristas é uma combinação do Estado, na forma democrática de governo, e da economia de mercado, uma evolução, em termos de refinamento e complexidade do mecanismo institucional, do Estado de Direito dos contratualistas. A construção do indivíduo como cidadão, detentor de direitos subjetivos e obrigações políticas e sociais, é também uma evolução a partir da concepção do indivíduo como pessoa, i.e., como detentor de direitos e obrigações civis. No entanto, se do ponto de vista da tecnologia, admitimos uma evolução 
entre os dois subprogramas, por outro lado, supomos haver uma ruptura entre as duas propostas no encaminhamento de suas justificações teóricas (idem).

\section{RACIONALISMO E CONTRATUALISMO}

O presente artigo propõe-se a apresentar o contratualismo como método para resolver problemas seguindo o modelo geométrico, o método analítico e o modelo atomista mecanicista da natureza. Como o objetivo é o de fazer da Política uma ciência, portanto, uma disciplina autônoma, a metodologia contratualista perseguirá esse objetivo tanto em relação à forma quanto ao conteúdo. Quanto à forma, este método assume que a organização do conhecimento é aquela do modelo geométrico e que o método de resolver problemas é o método analítico com o recurso dos experimentos mentais; quanto ao conteúdo assume como sua tese ontológica fundamental que a única entidade existente é o indivíduo racional e autointeressado. O problema é aquele de explicar cientificamente todos os fenômenos políticos e sociais sob essas condições ontológicas e metodológicas. Assim como Galileu estudou o movimento dos corpos, Hobbes, e com ele o programa contratualista, propõe uma teoria da ação humana como uma teoria do movimento (ação ou comportamento) do indivíduo. O modelo de racionalidade, central ao estudo da ação humana, é o modelo de escolha racional. Segundo esse modelo, os indivíduos possuem propósitos e, em função da racionalidade que lhes é imputada, são dotados da capacidade de ajustar os meios aos propósitos. Além disso, é suposto neste modelo um critério de escolha, e esse é apresentado por Hobbes como sendo aquele do maior benefício líquido ou, como diz o teórico, o "bem manifesto” (HOBBES, 1974, p. 42-43).

A questão central é, então, aquela de como explicar todos os demais fenômenos políticos e sociais a partir dessas teses. O problema concreto que Hobbes e os demais contratualistas abordam, no quadro teórico acima, é o de explicar porque existe o Estado e qual é a sua natureza, ou, como dito acima, o problema da emergência e estabilidade da cooperação. A metodologia contratualista elaborada para abordar esse problema sobre a cooperação ou sobre a natureza do Estado nos contornos do quadro teórico esboçado aqui apresenta-se sob dois aspectos: descritivo, por um lado, e normativo ou prescritivo, por outro. O aspecto descritivo é aquele envolvendo o objetivo de fazer da Política uma ciência, por meio do estudo das propriedades e das leis da natureza e da ação humana mencionado anteriormente. No aspecto normativo ou prescritivo, o propósito é o de elaborar, a partir deste conhecimento da natureza e da ação humana, instrumentos para a intervenção social e política na promoção de comodidades e bem-estar. A elaboração desses instrumentos de intervenção consiste, por exemplo, na construção de tecnologias políticas e sociais como aquela da configuração de instituições voltadas à realização de uma tarefa ou função, sendo a mais básica e fundamental aquela de proporcionar a cooperação entre os indivíduos interagentes. Essa concepção da Política e do Direito como ciência, elaborada pelos contratualistas, em particular por Hobbes, segue tanto a proposta de ordem metodológica do programa racionalista desenvolvido por Descartes, quanto os modelos e os procedimentos concretos e paradigmáticos de solução de problemas aplicados por Galileu. O programa racionalista elaborado por Descartes propõe-se a universalizar as conquistas metodológicas que ele mesmo desenvolveu com a proposta de algebrização da geometria, o que permitiu transformar a abordagem de resolver problemas na geometria, de uma arte em uma metodologia, assim como os métodos desenvolvidos por Galileu na construção da Física - em particular, o método dos experimentos mentais, abstrações do mundo físico para melhor acessar suas leis de funcionamento.

Deste modo, o contratualismo é aqui afirmado como um conjunto de recursos que consiste, seguindo o modelo da Geometria e da Física, em um método de construção de modelos, de procedimentos para combiná-los e organizá-los em novos modelos, particularmente do modelo do indivíduo como racional e auto-interessado, do modelo de racionalidade como um modelo de escolha racional e, também, a construção de medidas para fazer escolhas em termos do desempenho dos agentes ou dos instrumentos tecnológicos, entre eles, particularmente, a medida de custo e benefício. Esses instrumentos são, neste sentido, o que se denomina modernamente de análise econômica do Direito e da Política. O método de construção contratualista é o tema aqui encampado, tendo sido os modelos concretos contemplados em outros artigos (LEISTER \& CHIAPPIN, 2007a; 2007b). Como afirmado aci- 
ma, o programa de pesquisa da Política e do Direito como ciência consiste em um subprograma do programa de pesquisa epistemológico racionalista. O programa racionalista incorpora um conjunto de teorias que versam sobre as condições de possibilidade do conhecimento, portanto, fornecendo tanto abordagens epistemológicas quanto as metodologias que as operacionalizam (neste caso, essas metodologias incorporam métodos heurísticos de como construir teorias científicas). Como estruturado por Lakatos (1979, p. 109-243), o aparato metodológico dos programas de pesquisa sustenta que a sequiência de teorias que pertence a um mesmo programa compartilha um núcleo teórico comum, contendo seus principais pressupostos e uma heurística positiva. A heurística contém modelos, hipóteses auxiliares, técnicas de solução de problemas e métodos de construção de teorias. Todos esses elementos servem para aplicar o núcleo na solução de problemas.

O programa de pesquisa epistemológicometodológico racionalista, por sua vez, pode ser decomposto em três subprogramas: i) racionalismo clássico; ii) racionalismo neoclássico; iii) racionalismo crítico (CHIAPPIN, 1996). Afirmamos alhures que o contratualismo pertence ao projeto epistemológico e metodológico do racionalismo clássico, que é composto das teorias epistemológicas de Descartes, Locke, Hume e Kant. A tese principal pertencente a este programa é sustentar ele que conhecimento é conhecimento verdadeiro e certo, i.e., que a natureza do conhecimento é a certeza e que existe um método, o experimento mental, capaz de acessar esse conhecimento. O subprograma racionalista neoclássico tem como principais representantes as teorias epistemológicas de Duhem e Poincaré. A tese central do subprograma racionalista neoclássico é aquela que afirma que todo conhecimento é hipotético. A concepção de Duhem é um meio termo entre a metafísica e o relativismo e convencionalismo de Poincaré que, por sua vez, abdica de qualquer pretensão à verdade e adota uma postura instrumentalista-pragmática com relação à ciência, cujas teorias e modelos devem ter como função principal o fornecimento de boas previsões para uma determinada classe de fenômenos. Neste subprograma não há grande espaço para os experimentos mentais, uma vez que a avaliação de uma teoria é empreendida por meio dos testes de suas conseqüências. O racionalismo crí- tico, por sua vez, pode ser identificado à epistemologia popperiana, que não é outra coisa senão uma tentativa de operacionalizar a proposta de Duhem por meio da proposição de uma metodologia do falseamento e da proposta de estabelecer a possibilidade do conhecimento racional, ainda que sem um fundamento último, nem mesmo, a base empírica. Desses três subprogramas interessa-nos aqui apenas o primeiro, o racionalismo clássico, que é formado pelas teorias epistemológicas de Descartes, Locke, Hume e Kant e que contém os elementos básicos que formam tanto os pressupostos fundamentais quanto a caixa de ferramentas do contratualismo. O primeiro pressuposto, de ordem epistemológica, é o de que a natureza do conhecimento é a certeza. Esse pressuposto expressa a idéia de que o modelo é aquele da geometria e que o conhecimento deve ser organizado na forma geométrica, i.e., como um sistema axiomático, com poucos conceitos e poucas proposições ou princípios fundamentais. $\mathrm{O}$ segundo pressuposto é relativo à unidade epistêmica do conhecimento identificada como sendo aquela da proposição e da qual se afirma que é verdadeira ou falsa. Como o conhecimento deve ser certo, exige-se, então, de uma proposição verdadeira, que tenha, igualmente, a propriedade da certeza, significando com isso que ela deve ser justificada. A noção de justificação é aquela de prova ou demonstração, cujo modelo é o da geometria. Conhecimento, então, envolve a idéia de um sistema axiomático formado de conceitos e proposições em que alguns são tomados como primitivos e os demais obtidos por deduções e demonstrações a partir destes poucos por meio de regras de inferência. O conjunto dos princípios e conceitos tomados como primitivos é denominada como "base do conhecimento". O terceiro pressuposto aventa a existência de um método capaz de decidir com certeza com relação à verdade ou falsidade das proposições relativamente à base do conhecimento.

Contudo, a despeito do método, segundo o racionalismo clássico permanece o problema da garantia da verdade e certeza do conhecimento e das proposições que compõem a base. Faz-se, portanto, necessário um método para encontrar os primeiros princípios como proposições universais verdadeiras e conhecidas como certas. O método apropriado que o contratualismo adotou para elaborar os primeiros princípios como conhecimento certo é aquele dos experimentos men- 
tais de Galileu, e que Descartes também desenvolveu e sistematizou em sua obra Regras para a Direção do Espírito. Ambos, Galileu e Descartes, fizeram dos experimentos mentais os recursos para estabelecer as leis básicas como verdadeiras e conhecidas como certas. Descartes introduziuos na filosofia como parte de sua proposta da universalização do modelo geométrico e do método analítico como métodos científicos. Eles são construídos em torno da idéia de que os elementos essenciais para esse projeto são a ordem e a medida. Descartes considera que apenas o conhecimento certo pertence ao âmbito da ciência e, portanto, que o conhecimento provável não pode ser considerado científico (DESCARTES, 1971, p. 14). Esta é uma das características do que vem a ser conhecimento para os racionalistas clássicos, assim como para os contratualistas, e que tem conseqüências profundas tanto para a Política quanto para o Direito como ciência. No que diz respeito ao Direito, o impacto dessa concepção é na direção de uma reação contra a forma fragmentada e pouco coesa com que se apresentava o Direito Canônico. A organização, quando esta existia, era feita segundo a matéria, e não segundo a ordem. A pressuposição epistemológica de que a forma do conhecimento é aquela do modelo geométrico levou a um esforço de sistematização do Direito, começando com Grotio, e na direção de construí-lo como conhecimento, portanto, como um sistema hierarquizado e organizado em termos de harmonização conceitual e consistência lógica (WIEACKER, 1967). Essa concepção do Direito desemboca na sua construção como um sistema codificado, em contraposição à idéia do Direito Consuetudinário. O desenvolvimento do Direito entre essas duas formas alternativas encontrará o primeiro período de sua maturidade no final do século XVIII e começo do século XIX, com o debate entre Bentham (1843, p. 223-295) e Blackstone e com a resistência da forma consuetudinária na Inglaterra e da elaboração do Direito Constitucional, com o Código Napoleônico. Na medida em que o programa racionalista avança, se para Descartes são ciências a Metafísica, a Física, a Moral, a Mecânica e a Medicina, para Locke apenas a moral e a geometria são científicas, ao passo que, para Hume, o conhecimento certo é um conjunto vazio. A tentativa kantiana de recuperar o programa não se sustenta diante do progresso da ciência, que apontou para a falsidade de muitas das teorias científicas tidas por verdadeiras e que se mostraram falsas, como é o caso da teoria do calórico. Por esta razão, o programa de pesquisa racionalista clássico constitui-se em um programa degenerativo, nos termos em que Lakatos supõe ser degenerativo um programa de pesquisa. Mas qual seria a razão de se sustentar o racionalismo clássico como degenerativo? A compreensão desta degenerescência encontra-se na tese e na metodologia de que o conhecimento, para os clássicos, é conhecimento certo.

Em artigos anteriores, temos nomeado este método associado ao conhecimento certo como método fundacionista (LEISTER \& CHIAPPIN, 2007b). No método fundacionista, encampado pelo racionalismo clássico, uma proposição pode ser justificada - leia-se: ter seu valor de verdade assegurado - apenas quando um fundamento puder lhe ser imputado. Por outras palavras, justificar uma proposição significa apontar para o seu fundamento ou origem. Ato contínuo, a pergunta que se segue a esta afirmação é: e o fundamento, ele mesmo, como pode ser obtido? Para que não se recaia em uma regressão infinita, o fundamento é identificado a um axioma, uma verdade nãodemonstrável. Mas é esta verdade auto-evidente, como supunham os aprioristas ou intuicionistas? Esta não é nem a posição de Descartes, nem a do empirista Locke. Para ambos, é suposto existir um método capaz de acessar essas primeiras verdades, os fundamentos de todo raciocínio científico por meio dos quais todas as demais proposições poderiam ser justificadas. A exigência do método para estabelecer os fundamentos é de que, como este trata de um conjunto de regras, elas podem ser reproduzidas por qualquer um visando alcançar o mesmo resultado: esses fundamentos. A idéia vaga da intuição como um obscuro ato psicológico adquire, por aqui, uma formatação metodológica, valeria mesmo dizer, um algoritmo.

O método para se acessar os fundamentos ou primeiras verdades é o método analítico que faz do recurso à experimentação mental capaz de trabalhar com condições as mais gerais, abstratas e universais possíveis. Além disso, a experimentação ou simulação mental permite a construção teórica dos dados do problema e a colocação da questão com maior rigor e clareza. Essa abordagem permite o controle dos dados do problema e da formulação das relações entre eles. Desta forma, pode-se estabelecer uma relação de causa e 
efeito entre esses dados. Por aqui, pode-se manipular essas condições e estudar o efeito delas sobre algumas variáveis previamente isoladas. Assim, essa abordagem por meio de experimento mental procura isolar ou abstrair o objeto sob estudo do espaço e tempo e o submeter à análise de sua natureza, visando identificar suas propriedades essenciais e, então, o efeito que sua manipulação provoca em outras variáveis do problema. Tal método de construção e de experimentação mental é também o mais adequado para estabelecer os fundamentos de uma ciência. Ele é o meio de se acessar as proposições universais verdadeiras e, assim, o conhecimento certo. Como já atestamos, o modelo de justificação ou de explicação de uma proposição prescreve, para os racionalistas clássicos, que seu fundamento ou origem deva ser identificado. Como apresentado em artigos anteriores, o contratualismo clássico pode ser caracterizado como um (sub)programa de pesquisa incluindo uma seqüência de teorias - as de Hobbes, Locke, Rousseau e Kant - construídas a partir da aplicação da matriz epistemológica projetada pelo programa de pesquisa racionalista clássico. Se no racionalismo clássico, os fundamentos são essenciais no encabeçamento de um raciocínio científico, sendo as demais proposições justificadas a partir deles, a garantia da existência de um fundamento não é suficiente, sendo necessário um método capaz de acessá-lo e justificá-lo. A justificação das proposições verdadeiras por meio de um método é a condição para se ter um conhecimento certo. Um dos paradigmas deste método de experimento mental é o método da dúvida utilizado por Descartes para estabelecer os fundamentos de sua metafísica e da idéia da metafísica como ciência.

Apesar de sistematizado por Descartes para construir a sua Metafísica, este método pode ser imputado a Galileu e será também aquele adotado pelos contratualistas para construir a Política e o Direito como disciplinas científicas. O racionalismo de Locke rejeita a maior parte do que Descartes considerava como conhecimento certo. Segundo a análise de Locke, apenas a Matemática, a Geometria e a Moral satisfazem os requisitos para serem denominados de conhecimento certo, rejeitando a Metafísica e a Física. Segundo Locke, a moral é conhecimento certo, pois tem a mesma forma que o conhecimento geométrico, ou seja, ela é o resultado de uma construção mental (LOCKE, 1973, p. 286). A principal ilustração, utilizada por todos eles e, em particular, por Locke, é aquela do conceito ou definição de triângulo como figura de três lados da qual se extrai muitas proposições verdadeiras desta definição, como, por exemplo, aquela que afirma que a soma de seus ângulos internos é igual à soma de dois ângulos retos. Locke segue, na fundamentação da Política ou moral como ciência, o mesmo método e proposta de Hobbes na abordagem do problema da Política e do Direito como ciência e, por isso, enquadra-se no subprograma contratualista, assim como Rousseau e Kant.

Neste contexto, o método de construção contratualista constitui-se em um procedimento apto a buscar e acessar fundamentos que justificam e explicam as instituições políticas, particularmente, o Estado Civil (LEISTER, 2005). O contratualismo segue os ensinamentos e o sucesso da Física, tanto em explicar quanto em intervir na natureza por meio de tecnologias. A Física, que é mecanicista, considera a natureza como formada de umas poucas naturezas simples sujeitas também a um conjunto de leis simples que são capazes de explicar uma ampla gama de fenômenos. Essas naturezas simples da Física são os corpúsculos que tem as propriedades da extensão e do movimento. Todas as regularidades devem ser explicadas em termos das regularidades mecânicas que são formadas de um número pequeno de leis. A metafísica dualista cartesiana constrói a arquitetura ontológica, epistemológica e axiológica da natureza e do homem que conhece a natureza ajustada à concepção mecanicista. São duas substâncias: espírito (o cogito) e matéria (corpos). E, assim, são dois os domínios do conhecimento: o domínio do mundo da natureza espiritual e o domínio do mundo da natureza mecânica. Esses dois domínios vão se consolidar, com Kant, no domínio do reino dos fins que é governado pelas leis da liberdade e o domínio da natureza física governada pela lei da causalidade. A essência do espírito é a razão e a vontade, enquanto a essência da matéria é a extensão e o movimento. A metafísica cartesiana deverá explicar como o indivíduo como espírito pode conhecer o mundo enquanto extensão e movimento.

Para o contratualismo, elaborado por Hobbes, o indivíduo é identificado como o fundamento do mundo político, sendo a única entidade ontológica de existência real, todas as demais constituindose em composições artificiais formadas de indiví- 
duos. Ainda, esse indivíduo é abstraído de seu espaço e tempo, i.e., de seu ambiente social, por meio de um experimento mental, tal como aqueles construídos por Galileu e Descartes, e analisado em sua natureza. Por meio desse experimento umas poucas propriedades básicas do indivíduo podem ser identificadas, particularmente sua racionalidade, auto-interesse e liberdade. Em seguida, os indivíduos, essas naturezas simples com idênticas propriedades, portanto, assumidos como iguais, são colocados juntos, em interação. No conjunto de indivíduos em interação, cada um regulado pelo princípio da autonomia da vontade, de modo que o domínio desses indivíduos em interação é aquele das relações privadas em que se dão as relações pessoais, familiares e negociais. A partir da interação que se atribui a eles e de suas características, o contratualismo constrói o seu problema para o qual pretende trazer soluções e justificá-las. O problema que se constrói a partir dos indivíduos interagentes, que são racionais e auto-interessados, é aquele do surgimento e estabilidade da cooperação. As condições do surgimento e da estabilidade da cooperação tornam-se um problema ao assumir que os indivíduos em interação sustentam diferentes interesses que tendem a entrar em conflito por conta dessa diversidade e, ainda, porque dispõem de iguais capacidades para poderem satisfazê-los. Esse conjunto de dados transforma esse Estado de Natureza, pela ausência da presença do Estado, em um Estado de Guerra. Componente fundamental do método contratualista, o método analítico cartesiano de resolver problemas caracteriza-se, entre outras coisas, por requerer que se faça uma hipótese acerca da solução do problema. Com esta exigência, entende-se que a hipótese de solução, para os contratualistas, no que diz respeito ao problema do surgimento e da estabilidade da cooperação, é o Estado Civil. Assim, o verdadeiro objetivo da abordagem metodológica dos contratualistas é o de construir uma nova explicação das razões que justificam a existência do Estado Civil, qual é a sua natureza e a do poder político. O mundo interpretado como matemático e geométrico não comporta mais a resposta aristotélica de que o homem é naturalmente um homem político e social. Os novos instrumentos do estudo da natureza requerem também novos estudos sobre a natureza humana. Assim como os átomos são entes mecânicos e não naturalmente verdes ou amarelos.
A questão que surge é a do por que existem as cores ou, dito diversamente, do por que existem as outras coisas? A resposta dos clássicos é que elas são formadas de átomos. Coloca-se, então, uma nova questão: por meio de quais leis? A descoberta dessas leis e das relações que elas expressam é o objeto da investigação e, no caso contratualista, trata-se da descoberta das relações políticas e sociais. O Estado Civil como hipótese de solução do problema deve ser tratado como mais um dado deste problema. A abordagem do método analítico de solução de problemas requer que se busque, então, o elemento intermediário, a medida, a razão, na linguagem cartesiana, capaz de relacionar os termos do problema construindo uma seqüência de proposições que levem dos dados iniciais até o dado que expressa a solução do problema. No caso do contratualismo, significa instituir um método para buscar e auferir a medida que conecta o Estado de Natureza, formado de indivíduos racionais e auto-interessados em interação, ao Estado Civil. Este é o procedimento que nomeamos aqui método contratualista. $\mathrm{O}$ termo médio entre o problema da cooperação e sua solução é identificado pelo contratualismo como sendo o contrato social, o fundamento do Estado Civil. Em Descartes, o que caracteriza o conhecimento científico é o método e a aplicação do método, que consiste na ordem e na medida, mais do que o corpo de conhecimento propriamente dito. O contratualismo, como subprograma do racionalismo clássico, segue esse compromisso. É o procedimento metodológico, mais do que seu sistema teórico, que é retomado pelos contratualistas modernos, dentre os quais Rawls.

\section{O MÉTODO DE GALILEU: EXPERIMEN-}

\section{TOS MENTAIS COMO MÉTODO}

Se, por um lado, a ênfase na idéia do contratualismo como um método é uma das principais idéias organizando o desenvolvimento deste artigo, por outro lado, assume-se aqui existir um profundo vínculo entre este método e aquele adotado na Física de Galileu. Como Galileu toma a geometria como forma de organização do conhecimento, assume também a idéia de que seus princípios são verdadeiros. Qual método proporciona uma ciência com proposições universais verdadeiras e conhecidas com certeza? O método de experimentos mentais poderia ter essa função e Galileu fez uso desse método para dar fundamentos às leis básicas do movimento dos corpos, 
em particular em seu estudo sobre a lei da queda dos corpos e a da inércia. As experiências do pensamento são experiências construídas com recursos mentais, i.e., construídas com recursos de corpos-idéias, e não corpos-reais dotados de peso, cor, gosto e sujeitos a ações de todo tipo de forças. As experiências mentais fazem uso de corpos que são formas geométricas, situadas não em um espaço físico, mas em um espaço ideal que é o espaço geométrico da geometria euclidiana. Eles são modelos ou representações simplificadas da realidade. A possibilidade de construção de uma experiência mental que deu origem ao verdadeiro conceito de experimentação em Física decorreu de um desenvolvimento que durou centenas de anos e que dependeu fundamentalmente de três elementos: i) a destruição do cosmo aristotélico e a geometrização do espaço físico; ii) a física do impetus; e iii) a matematização da natureza (KOYRÉ, 1966).

O cosmo aristotélico era um mundo fechado, portanto finito, no qual cada coisa tinha seu lugar, sendo por ele definida. Sua característica principal era que se tratava de um espaço físico real, portanto com um centro bem definido e heterogêneo. Os corpos neste espaço tinham sua natureza definida também pelo lugar que ocupavam. $\mathrm{O}$ cosmo era dividido em duas regiões, a região sublunar e a região celeste. Os movimentos naturais dos corpos só podiam ser perfeitos, em linha reta ou circular. Esses movimentos naturais seguiam leis diferentes para essas regiões diferentes. Não havia vácuo. Todo movimento precisava de uma causa ou um motor. O movimento não era um estado, mas um processo. $\mathrm{O}$ repouso era um estado em que se encontra um corpo quando em seu lugar natural. A ausência de vácuo, portanto, a presença de um meio físico era fundamental para tornar, por meio da resistência, o movimento dos corpos finitos e também para explicar o movimento de um corpo quando sua causa não se encontrava presente, como no caso do movimento dos projéteis. A discussão aqui está muito relacionada com a abordagem de Koyré (idem, p. 13-79) sobre o cosmo aristotélico e a passagem do mundo finito para o universo infinito.

A utilização da teoria do impetus vai tornar dispensável a presença de um meio para explicar o movimento. Por outro lado, a utilização da física arquimediana para explicar o movimento de um corpo imerso neste meio torna, também, a pre- sença do meio dispensável, uma vez que mostra que, mesmo no caso de resistência nula - portanto, ausência de meio -, a velocidade atingida era finita. Desta forma, um dos passos na destruição deste cosmo foi construir a possibilidade teórica de pensar o vácuo. E, além disso, o uso desta mesma física (hidrostática) arquimediana para estudar o movimento dos corpos levou a pensálos em termos de densidade. Com a associação deste conceito ao de corpo, pode-se destruir a noção aristotélica de corpos pesados e leves em termos absolutos, pois a densidade é um termo relativo. Na seqüência deste raciocínio chegou-se à consideração teórica de que qualquer corpo mais leve do que o seu meio poderia continuar subindo sem limites. Com estes recursos, o mundo aristotélico foi transformando-se de um mundo finito para um mundo sem limites, ou seja, para um universo e, simultaneamente, seu espaço físico heterogêneo foi se homogeneizando e, assim, transformando-se em um espaço geométrico da geometria euclidiana. $\mathrm{O}$ aparecimento da física do impetus permitiu interpretar o movimento dos projeteis sem a necessidade do meio como um motor, pois o corpo teria o movimento impresso em seu próprio corpo, portanto, não precisaria de um motor a ele acoplado nem precisaria manter qualquer relação com seu lugar natural. Desta forma, um corpo poderia ser definido sem relação com o espaço físico e o seu lugar nele. Por aqui, ele também foi transformando-se em um corpo geométrico. Com essa transformação pôde-se construir a noção de corpo isolado independente dos demais corpos que o rodeiam e do espaço que ocuparia. Essa noção, corpo isolado, tornouse central para o posterior estudo da lei da inércia. O corpo isolado, transformado em geométrico, e o espaço físico, também transformado em geometria, constituíram-se nos componentes fundamentais das experiências teóricas, uma vez que são experiências realizadas com um corpo ideal em um espaço ideal. Estabeleceu-se assim uma correspondência entre corpos no mundo e corpos ideais e entre o espaço físico e o espaço geométrico e entrou-se, por este meio, na teoria da representação, demarcando de maneira nítida o limite entre o mundo antigo e o mundo moderno. Com o mundo da ciência moderna o objeto imediato do conhecimento é a idéia, a representação de coisas no mundo, sendo estas os intermediários entre o indivíduo que conhece e o mundo a ser conhecido. A relação entre as representações do mundo e o mundo propriamente dito só é possí- 
vel com a geometrização do espaço e de seus corpos. A relação isomórfica entre eles é que torna possível estudar o mundo por meio de representações, por meio de modelos. É deste modo que se pode construir experimentos mentais sobre o mundo. Tais experimentos mentais expressariam condições gerais e universais e, por esse meio, seriam apropriados para conduzir à formulação de proposições universais sobre o funcionamento da natureza, constituindo-se, também, no meio de construir experimentos reais para testar essas formulações. E, como tais, eles permitiriam a elaboração de uma experimentação programada para avaliar uma determinada informação sobre a natureza. Ele seria um procedimento controlado para avaliar certas formulações sobre o modo como a natureza comporta-se.

O conhecimento moderno começa sempre pelas idéias ou representações que são os objetos imediatos do pensamento. De agora em diante tornou-se necessário resolver sempre o problema transcendental quanto às garantias que temos de que aquilo que pensamos ou representamos existe no mundo e lhe é correspondente. Não há mais lugar para o realismo ingênuo dos antigos. Esse problema transcendental só é possível com a aquisição da noção da representação como distinta das coisas representadas e de sua relação com ela. Este é o contexto trazido pelo surgimento da ciência moderna. A partir daí, torna-se possível falar em experiência construída teoricamente, envolvendo condições ideais tanto dos corpos quanto dos espaços e tornando possível a formulação da lei da inércia. A formulação dessa lei requer um conjunto de pré-requisitos sem os quais é impossível mesmo pensá-la. Essas experiências foram construídas em termos de representações, ou seja, por meio de modelos do corpo isolado, representações simplificadas da realidade, movimentandose em um espaço geométrico com condições específicas planejadas para proporcionar resultados antecipados que devem ser avaliados. Por exemplo, uma experiência construída teoricamente por Galileu é aquela em que se assume uma representação de corpo isolado que é colocado para movimentar-se em um modelo formado de dois planos inclinados com o mesmo ângulo - mas que pode ser calibrado - e separados por certa distância, esta também podendo ser controlada. Com essa experiência, além de prenunciar a lei da inércia, Galileu pôde formular ou sustentar o princípio de que, no movimento uniformemente acelerado, a velocidade depende apenas da altura do plano inclinado. Assumindo ser possível diminuir sistematicamente a aspereza ou a fricção proporcionada pelo suporte, tornando assim uma superfície física em uma superfície geométrica, pode-se imaginar que não há nenhuma força agindo sobre o corpo que desce uma rampa e sobe a outra. Nestas condições, não há razão para não inferir que a altura alcançada pelo corpo na outra rampa é a mesma da primeira.

Esta experiência pode ser acompanhada de uma experiência real. No entanto, é a experiência do pensamento ou teórica que dirige o que esperar na experiência real e, portanto, diz o que se deve observar e, por aqui, a interpretação da experiência real. Na seqüência do experimento teórico pode-se, agora, alterar a inclinação da rampa e o mesmo pode suceder com a experiência real, repetindo o mesmo tipo de raciocínio. Do mesmo modo, pode-se também alterar a composição do corpo, sua massa e tamanho e avaliar o impacto de cada um deles sobre o movimento. Desta forma, Galileu, por meio das experiências teóricas, conduzindo as experiências reais, pôde sustentar o princípio segundo o qual o grau de velocidade do corpo só depende da altura da rampa e não de sua inclinação ou de outras características do corpo. E, principalmente, obteve a idéia intermediária que levou à lei deste movimento. As experiências teóricas permitem também realizar aquilo que não é possível do ponto de vista prático, por exemplo, realizar operações que envolvem distâncias infinitas ou infinitas repetições das diversas circunstâncias envolvendo a experiência, como, por exemplo, no caso do plano inclinado, inclinações cada vez menores. E, com isso, poder inferir que esse movimento do corpo sobre uma superfície na ausência de forças, como é o caso da superfície geométrica, não terá fim e manterá a mesma velocidade, pois ela depende apenas da altura da rampa, e não da inclinação. Essa orientação sobre o que esperar e observar, obtida por meio dos experimentos mentais, é fundamental, uma vez que a experiência real nunca reproduz fielmente os resultados previstos pela teórica, embora os erros ou diferenças entre elas possam ser explicados convincentemente, e essas explicações possam ser testadas novamente.

Essas analogias aumentam a capacidade heurística desse método das experiências teóricas e abstratas, pois são capazes de eliminar as características concretas do fenômeno para con- 
centrar-se apenas naquilo que é determinante nele e, também, permitem transformar uma experiência complexa em outra equivalente mais simples. Com essa metodologia de construção e realização de experiências tanto teóricas quanto reais, Galileu construiu as evidências para os seus mais importantes princípios, em particular a lei da inércia, a lei do movimento uniformemente acelerado e o princípio da independência do movimento vertical e horizontal. Com eles, pôde explicar o movimento dos projéteis e demonstrar que a curva da trajetória deste movimento era uma parábola, ou seja, uma equação do segundo grau. Com esse conhecimento do movimento dos corpos, particularmente com a lei da inércia, construiu as condições de possibilidade da aceitação do sistema copernicano. Essa maneira de construir experiências teóricas para estabelecer princípios e deles deduzir geometricamente outros resultados tornou-se paradigmática do método de trabalho da Física matemática, proporcionando a descoberta das principais leis da cinemática, tendo sido transformado em modelo de método com Descartes, que o sistematizou e o elevou a objeto de estudo, para fazer de qualquer disciplina uma ciência, em particular, a sua metafísica e, no caso de Hobbes, a política.

\section{O MÉTODO DE DESCARTES: A DÚVIDA METÓDICAEA CONQUISTADAS PRIMEI- RAS VERDADES}

Temos, portanto, como tese, que são essas experiências e esse método de construir experiências teóricas ou do pensamento - as quais permitem muitas analogias e aumentam a capacidade e a heurística de resolver problemas - que constituem o modelo do método de resolver problemas de Descartes - o método analítico - e também do contratualista, de Hobbes, Locke, Rousseau e Kant. Esse método é descrito nas Regras para Direção do Espírito e no Discurso do Método e, aplicado, particularmente, como método da dúvida, nas Meditações Metafisicicas, a fim de alcançar os fundamentos da metafísica. O método da dúvida é uma experiência mental que tem por objetivo estabelecer e encontrar os fundamentos da metafísica com um conhecimento que se propõe certo (LEISTER, 2005). Ela é uma dúvida metodológica e artificial, não uma dúvida real, construída para a realização de uma tarefa que é a de resolver o problema das condições de possibilidade do conhecimento. A solução desse proble- ma envolve aquele de construir a base do sistema de conhecimento em uma concepção de conhecimento que exige como natureza deste a certeza. Assim, o conhecimento das primeiras verdades também deve ser um conhecimento certo, o que significa dizer, conhecimento justificado. A justificação de um teorema é a sua prova a partir dos conceitos e dos axiomas. Mas como justificar a verdade dos axiomas? Descartes pretende, com o uso do método analítico, como Galileu, resolver esse problema e, por ele, conduzir aos princípios fundamentais e às naturezas simples de seu sistema filosófico. Em Galileu, o principal modelo é aquele de um corpo isolado com massa e movimento. Em Descartes, segundo defendemos aqui, o sucedâneo do modelo do corpo isolado de Galileu é aquele do cogito e, em Hobbes, o modelo de indivíduo. Descartes segue Galileu e também constrói um experimento mental com o uso do método analítico para estabelecer sua base de conhecimento e resolver o problema das condições de possibilidade do conhecimento. Esse método de experimento mental é o método da dúvida. Desta forma, consideramos o trabalho de construção e solução do problema das condições de possibilidade do conhecimento, empreendido por Descartes nas Meditações Metafísicas (1967, p. 375-413) - com a conquista das primeiras verdades -, exatamente o análogo dos procedimentos de Galileu, que com seus experimentos mentais formulou leis fundamentais, como a lei da inércia e do movimento uniformemente acelerado. E, do mesmo modo, vamos considerar o trabalho de construção e solução do problema do estabelecimento, com Hobbes, das condições do surgimento da cooperação entre indivíduos interagentes, como sendo exatamente o análogo do problema de Galileu e de Descartes. Hobbes foi um dos autores dos quais Descartes editou tanto as objeções (idem, p. 599-631) a vários pontos das Meditações Metafisicas, quanto as suas próprias respostas a elas.

Descartes segue Galileu na solução do problema das condições de possibilidade do conhecimento, com o método da dúvida. Na busca da solução é fundamental a idéia do método analítico segundo a qual a hipótese de solução do problema deve ser colocada como um dos dados do problema. No caso do Descartes das Meditações, as hipóteses de soluções são aqueles do indivíduo e de Deus. Mas quem são eles, e quais são suas naturezas? São os dados do problema que vão 
definir. O estabelecimento da existência do indivíduo como racional e da existência de Deus como veraz está relacionado com os dados do problema e são alcançados apenas com o aparato de experimentos mentais e hipóteses auxiliares como a do "Gênio Maligno". A transição da existência do indivíduo para existência de Deus é feita por meio de uma medida que é a lei da causalidade. Não há dúvida que esses elementos fazem parte dos dados do problema. A questão está em encontrar uma idéia que liga os dois com força de prova ou de demonstração, ou seja, exigindo uma relação universal e necessária.

O modelo do corpo isolado de Galileu é o modelo do cogito para Descartes, aquele do indivíduo isolado da história e de suas relações sociais. Assim como Galileu estudou a natureza do corpo, Descartes estuda a natureza do indivíduo, aquela que subsiste para além das contingências. Segundo o teórico, essa natureza é a de uma substância pensante. Portanto, o resultado da aplicação do método analítico permitiu estabelecer um processo de como trabalhar para buscar e alcançar os fundamentos de qualquer disciplina e não mais apenas os da Física. O método, não o objeto, é o que define a natureza da ciência, como afirma o próprio Descartes. Para o filósofo francês, seguindo o modelo geométrico, esses fundamentos devem ser poucas naturezas simples. Além disso, cabe encontrá-las ou, melhor, expô-las de maneira aceitável, uma vez que constituem a base do conhecimento certo. A partir delas, procura-se construir uma seqüência de proposições que sustentam as proposições já estabelecidas e reconhecidas como verdadeiras, que são as regularidades empíricas. Apenas e tão somente neste caso, de ter uma seqüência de proposições que as sustentam, que podemos falar de regularidades empíricas conhecidas com certeza e, portanto, constitutivas de um conhecimento. Descartes segue aqui o exemplo de Galileu, que construiu a cinemática por meio de um processo de decomposição do complexo no simples, encontrando suas naturezas as mais simples que são o corpo definido como massa e com movimento que se dá como relação entre espaço e tempo.

Assim como Galileu, portanto, Descartes também pretende encontrar os fundamentos últimos por meio dos quais possa fazer da metafísica uma ciência e nela estabelecer as condições de possibilidade do conhecimento. E isso deverá ser feito partindo-se de uma situação em que não se tem nenhum conhecimento prévio. Descartes utilizará de um método semelhante ao de Galileu, pois, afinal, o propósito é o mesmo; Descartes apenas refletiu sobre o método e o sistematizou dando uma forma mais operacional. Com esta reflexão, Descartes promoveu o método de Galileu a um método de fazer de uma disciplina ciência, e não apenas a um método restrito à Física. Ele o denominava de método analítico e sintético, como Galileu. A natureza deste método era o mesmo da geometria que consistia em trabalhar com poucos conceitos e poucos princípios. Estabelecida uma base do conhecimento com esses requisitos o objetivo era o de resolver problemas no interior deste quadro teórico. Para isso, o ponto de partida é assumir o problema como resolvido, buscando, o método analítico, inicialmente construir um problema bem definido, que conta com três elementos: i) os dados, que são as naturezas simples e princípios, além de outras informações mais específicas relativas ao problema; ii) a questão; e iii) uma hipótese sobre a solução.

Esta hipótese de solução é, então, assumida como um dado do problema e o objetivo do método é encontrar a idéia intermediária ${ }^{1}$ que conecta os dados, formados das naturezas simples e dos princípios do sistema no qual está se enquadrando o problema, com a hipótese da solução. Quando é preciso construir a base do conhecimento, é preciso, então, adicionalmente, fazer uso de experimentos mentais que servem para estabelecer os componentes da base como conhecimento certo. O método da dúvida terá o formato desse método analítico combinado com a experiência mental, uma vez que ele é um método para estabelecer as bases da metafísica de Descartes, que quer construí-la como conhecimento certo. Assim, ele vai ser utilizado para encontrar ou mostrar como encontrar as naturezas simples e os princípios de seu sistema filosófico. O processo para abordar essa questão, e resolvê-la, requer, como afirma-

\footnotetext{
${ }^{1}$ Locke (1973, p. 286). Locke, falando do método encontrado nas escolas dos matemáticos, diz: "A arte de encontrar provas, e os métodos admiráveis que inventaram para assinalar e estabelecer em ordem estas idéias intermediárias, que demonstrativamente mostram a igualdade ou desigualdade de quantidades inaplicáveis, e isto que os conduziu tão longe e produziu estas maravilhosas e inesperadas descobertas" (idem, p. 324).
} 
mos, montar, inicialmente, um problema bem definido. O método da dúvida, como um método analítico, funciona, desta forma, como um método de construção, pois tem por objetivo definir bem o problema. Isso significa que deve fornecer i) os dados, ii) a questão e iii) proporcionar a hipótese de solução do problema e, então, iv) testar se a hipótese de solução é, de fato, a solução. Em caso positivo, deve-se, então, agregar essa solução como um novo dado e seguir adiante na ordem das razões para obter novas conseqüências. Trata-se claramente de uma experiência do pensamento, no sentido de ser artificialmente construída e planejada para realizar uma tarefa que consiste na exposição justificada de como chegar e obter aquelas verdades que constituem o fundamento de seu sistema filosófico, a partir dos quais todos os problemas devem ser enquadrados. A apresentação do processo pelo qual as verdades podem ser obtidas constitui, ao mesmo tempo, um processo de legitimação e explicação do porquê daquelas verdades e não de outras. O processo serve assim como um recurso de persuasão e convencimento daqueles que seguem o processo quanto ao valor e legitimidade daquelas verdades, as primeiras. Construída a base teórica, outras proposições são testadas relativamente a ela, por meio de inferências. Desta forma, como pode ser notado, falamos de um método em duas etapas, a primeira que possibilita acessar as primeiras verdades que formam a base teórica, a segunda, que visa avaliar o valor de verdade das proposições relativamente à base teórica. A seguir, apresentamos a aplicação dessa abordagem na construção do método contratualista, que visa fazer da Política e do Direito disciplinas científicas.

\section{O MÉTODO CONTRATUALISTA: O CON- TRATUALISMO CLÁSSICO}

O objetivo agora é desenvolver a tese de que o contratualismo pode ser considerado como uma metodologia baseada nos modelos de Galileu e Descartes. Ele é o método com o qual se pretende fazer da Política e do Direito ciências. O núcleo metodológico, já mencionado acima e, também, em outros lugares (LEISTER \& CHIAPPIN, 2007a; 2007b), é composto do pressuposto de que a única entidade real do mundo social é o indivíduo - que tem como propriedades ser racional e auto-interessado -, do modelo de escolha racional como modelo de racionalidade e da medida de avaliação como aquela do custo-benefí- cio, além de uma heurística de modelos. Essa metodologia compõe-se de uma parte descritiva e de uma parte normativa. A parte descritiva tem por objetivo o estudo científico da natureza e da ação humana. A parte normativa visa construir tecnologias, a partir deste conhecimento da natureza e da ação humana, com o propósito de resolver o problema do surgimento da cooperação. Como mencionado, o problema fundamental dos contratualistas, em particular de Hobbes, é paralelo àquele de Galileu: construir os pressupostos da Física mecânica como as condições da aceitação do sistema copernicano, i.e., da aceitação do sistema heliocêntrico.

O problema de Hobbes e dos contratualistas é aquele das condições de possibilidade do surgimento e da estabilidade da cooperação, entendido que a resposta a este problema é dada empiricamente e identificada como o Estado que se coloca como promotor, por meio de sua capacidade de poder, do interesse comum. Contudo, resta saber e compreender qual é a natureza e a origem do Estado como poder político e, principalmente, qual é a fonte de sua legitimidade. Enfim, por que existe o Estado e não apenas a liberdade natural? O tratamento dado a esse problema por Hobbes é elaborado nos mesmos moldes que na nascente ciência natural moderna. Uma das principais hipóteses da ciência natural para construir explicações dos fenômenos físicos era interpretar a natureza física de acordo com o modelo geométrico, envolvendo poucos conceitos e postulados, como constituída de poucas naturezas simples, no caso, de corpúsculos, e também dotada de poucas propriedades, como massa e velocidade. Todos os fenômenos físicos seriam resultados da interação e choque destas partículas e das leis governando seus comportamentos. A explicação dos fenômenos físicos por meio deste atomismo mecânico foi denominada "explicação mecânica". Galileu valorizou essa hipótese com a sua contribuição sistemática para a geometrização do espaço físico (KOYRÉ, 1966) e com os corpos transformados em objetos geométricos dotados de poucas propriedades, como forma, densidade e movimento.

Hobbes seguirá o mesmo modelo de abordagem de Galileu no estudo das relações de poder entre os indivíduos interagentes que dão origem à sociedade. Esta será modelada como formada de indivíduos interagentes, semelhante à considera- 
ção dos gases como o resultado de corpúsculos interagentes. E o indivíduo será estudado por Hobbes do mesmo modo que Galileu estuda o movimento de um corpo, de sorte que, assim como Galileu geometriza o espaço físico, Hobbes geometriza o espaço social e político. Neste espaço, ele estabelece uma nova ontologia, que consiste do indivíduo isolado como única entidade existente dotada de algumas poucas propriedades. Com isso, ele pode estudar a natureza do indivíduo e, então, estudar sua ação, seu comportamento. As propriedades que Hobbes atribui ao indivíduo são exatamente aquelas determinantes do seu comportamento: racionalidade e auto-interesse. $\mathrm{O}$ auto-interesse representa a idéia de que o indivíduo tem um propósito e preferências e que estas vêm sempre antes das preferências dos demais. O principal propósito do indivíduo é a autopreservação, sendo ela o objetivo maior de sua ação.

A razão torna eficiente a realização deste fim, visto que a racionalidade está relacionada com a escolha entre os meios ou ações utilizadas para realização destes propósitos. Com mais precisão, é preciso dizer, contudo, que para Hobbes a racionalidade não é uma faculdade inata, mas adquirida a partir da invenção da linguagem e do processo de aprendizagem, dando um caráter evolutivo, ainda que pouco perceptível, para sua abordagem. Hobbes procura então construir uma teoria da natureza e da ação humana. A teoria da natureza humana de Hobbes revela que a ação humana segue os princípios da racionalidade, o que significa dizer que o indivíduo escolhe os meios adequados para realizar e perseguir seus fins, e isto por meio da capacidade de realizar inferências dos efeitos a partir das causas. Segundo Hobbes, ciência é o conhecimento de como a causa produz o efeito. O conhecimento científico, que é o conhecimento racional, também traz eficiência no sentido que permite fazer uma avaliação antecipada das ações disponíveis e, então, a escolha de uma dentre essas ações para a realização de seus fins. Por meio deste recurso, ele escolhe as ações mais adequadas aos seus propósitos. Como a razão deve ir das causas aos efeitos, ele usa a razão para extrair todas as conseqüências de uma determinada ação na busca de um fim. Ele avalia essas conseqüências em termos de custos e benefícios e, então, escolhe aquela que maximiza o benefício líquido. Essa avaliação requer a construção de uma medida deste benefício líquido. Essa avaliação de modo antecipado é exatamente o que Hobbes considera como um estudo científico da ação humana. Procedendo do mesmo modo com todas as demais ações disponíveis pode-se, então, estabelecer uma métrica para comparar ações e escolher a mais eficiente, aquela que apresenta o maior benefício líquido. Desta forma, pode-se dizer que a lei fundamental do comportamento humano é que um indivíduo em busca da realização de seu auto-interesse escolhe a ação cujas conseqüencias maximizam seu benefício e minimizam seu custo. Esse é o primeiro conjunto dos dados do problema: o indivíduo e suas propriedades.

O segundo conjunto de dados é o espaço no qual os indivíduos, com essas propriedades, são colocados para interagirem. Esse espaço é o das relações sociais e políticas, é o "Estado de Natureza”. Ele é geometrizado por Hobbes, sendo um modelo formado de indivíduos racionais e autointeressados interagentes. Com o conhecimento da natureza humana e da lei de sua ação, Hobbes constrói um modelo formado de indivíduos interagentes. Ele é um modelo de indivíduos interagentes sem a presença do Estado, daí "Estado de Natureza". Esse modelo do Estado de Natureza tem semelhança com o modelo de Galileu no estudo da lei de movimento, o modelo de um corpo isolado em movimento ou em repouso sem a presença de forças agindo sobre ele. Essa lei é a lei de inércia que afirma ser a tendência do corpo a permanecer em seu estado seja em repouso ou em movimento retilíneo uniforme. Outrossim, a questão que se pode colocar em Hobbes é sobre qual seria a tendência (o estado) de um conjunto de indivíduos racionais e auto-interessados em interação sem a presença do Estado Civil. A resposta é que seria aquele de um "Estado de Guerra", de uma guerra de todos contra todos. O modelo aqui é o de Descartes, de uma pedra amarrada em uma corda e sendo girada em circulo, por uma mão que define tanto o tamanho da corda que a prende quanto a velocidade com que ela gira. É essa mão e a corda que mantêm a pedra girando em circulo. Assim será o Estado Civil. É o Estado que impõe o movimento ordenado dos indivíduos na sociedade por meio de suas regras e leis.

Essa construção é orientada no sentido de que Hobbes tem intenção de estudar a natureza da instituição denominada de poder político ou Estado 
Civil. A pergunta que se coloca é de que, dado que os indivíduos são auto-interessados e racionais, por que existe o Estado? Porque não existe apenas a liberdade humana? No entanto, para que essa questão seja bem colocada, é preciso completar os dados acima. Qual seria a descrição mais correta deste Estado de Natureza sem a presença do Estado? Hobbes pressupõe que, nestas circunstâncias, os indivíduos são iguais no sentido de que todos têm condições e capacidades de tirar a vida um do outro e também são iguais na esperança de realizarem seus propósitos. O modelo do Estado de Natureza pode ser interpretado, inicialmente, como um mercado competitivo de poder, uma vez que cada indivíduo encontra-se no mercado e compete em posição de igualdade com relação aos demais $^{2}$. Neste estado, novas propriedades do indivíduo são explicitadas, sendo estas decorrentes da interação com os demais indivíduos: a primeira delas é que os indivíduos são totalmente livres; a segunda é que eles são iguais no sentido de possuírem a capacidade de destruir o outro; a terceira é que o propósito de cada indivíduo é a conservação da vida; a quarta é que a relação entre os indivíduos é uma relação de poder. Poder é a capacidade de um indivíduo de fazer com que o outro aja de acordo com o seu auto-interesse, i.e., o interesse do primeiro indivíduo.

A questão que se coloca no contexto deste conjunto de dados é quanto à natureza deste Estado de Natureza. Neste, o indivíduo racional e autointeressado reconhece-se com direito à vida e, como tal, reconhece um direito natural, a saber, que cada indivíduo tem o direito de usar todos os recursos, inclusive destruir o outro, como um meio para realizar seu propósito de auto-conservação. Esse direito é a principal regra regulando as relações de poder que caracterizam as interações entre os indivíduos. O recurso com que cada indivíduo conta para realizar seus objetivos é denominado por Hobbes de capacidade de poder. A razão, que é o recurso pelos quais se avaliam os meios para a realização dos objetivos, requer um aumento incessante de sua capacidade de poder para promover sua auto-conservação, uma vez que não há como conhecer previamente

2 O mercado de poder hobbesiano pode ser, em última instância, reduzido ao mercado de recursos escassos, uma vez que poder é definido não como o propósito último dos indivíduos, mas como um meio a partir do qual são alcançados os bens necessários para a sobrevivência do indivíduo. a capacidade de poder dos demais indivíduos. Essa é uma propriedade do mercado de competição por poder, decorrente da informação imperfeita que é característica das interações de poder entre os indivíduos que procuram sobreviver no Estado de Natureza.

O modelo do Estado de Natureza descreve, então, o domínio das relações privadas, no qual eles desenvolvem suas relações pessoais, familiares e comerciais. A lei fundamental regendo a relação entre os indivíduos, neste domínio, é o princípio da autonomia da vontade. Os indivíduos são livres e iguais em todas as suas relações e entram nelas, livremente, dependentes apenas de suas vontades. Esses indivíduos reconhecem, cada um, seu direito à propriedade da vida (mas apenas da sua) e, para isso, reconhecem também, logicamente, seu direito ao meio de garantir esse fim. Esse meio é o direito natural de usar todos os recursos para se auto-preservar. Não há como compatibilizar os quatro elementos básicos do modelo do Estado de Natureza, ou seja: i) que os indivíduos são plenamente livres, no sentido de deterem o direito de natureza; ii) que os indivíduos são iguais na capacidade de destruir um ao outro e de ter esperança de realizar seus propósitos; iii) que os indivíduos são auto-interessados e buscam se conservar por todo o tempo que a natureza permite; iv) que os indivíduos são racionais no sentido de avaliarem as ações mais eficientes na realização de seus propósitos em termos de custos e benefícios e escolher aquela que maximiza seu benefício líquido. São esses quatro elementos que transformam o Estado de Natureza em uma tendência ao Estado de Guerra.

Neste contexto, com todos esses dados, coloca-se a questão de como é possível fazer surgir a cooperação, ou como a paz é possível, ou, ainda, como é possível garantir o direito à vida. Agregase a esse problema, como uma nova informação, o terceiro conjunto de dados, segundo a estrutura do modelo de solução de problemas indicado pelo método analítico. Esses novos dados consistem na elaboração de uma hipótese sobre a solução que de fato existe no mundo real, i.e., o Estado Civil. A solução do problema inicial desloca-se para a busca da idéia intermediária que liga os dois conjuntos de dados iniciais, os modelos de indivíduo e Estado de Natureza, com o terceiro conjunto, o modelo de Estado Civil. Essa idéia intermediária deverá responder à pergunta de por que existe $\mathrm{o}$ Estado e qual é a sua natureza. A resposta, fornecida 
empiricamente, é de que ele existe para exercer a função de garantir a cooperação entre os indivíduos interagentes. A questão desloca-se, então, de por que existe o Estado para por que não existe apenas a liberdade natural, i.e., por que a liberdade natural não é capaz de produzir a cooperação. Uma vez respondida essa questão, o foco voltase novamente para o Estado Civil como solução e, então, a questão é quanto à sua natureza e sua legitimidade. Essas respostas referem-se às condições de surgimento e estabilidade da cooperação. A busca, então, é, como afirmado acima, seguindo o método analítico, pela idéia intermediária que conecta os dados com a hipótese de solução, mas não para explicar o Estado Civil, como Descartes explicava o arco-íris ou Galileu, a lei da queda dos corpos, pois, naquele caso, estávamos falando de ciência natural, enquanto, em Hobbes, estamos no domínio da política e da moral.

O problema, tal como o percebe Hobbes, é que indivíduos auto-interessados e racionais em busca da realização de seus fins, quaisquer que sejam eles, têm que garantir antes de tudo o primeiro deles que é sua auto-preservação, por tanto tempo quanto sua constituição natural lhe permita. Eles perseguem, portanto, a realização do direito que reconhecem ter: o direito de propriedade da própria vida. Passam, então, a avaliar as ações mais adequadas para alcançar esse fim. Com essa estrutura do problema, Hobbes deixa claro que o interesse comum, aquilo que é comum a todos os indivíduos, é a segurança coletiva, sendo esta o seu principal valor. Ele impõe uma restrição à solução, ou seja, a solução tem que ser capaz de realizar esse valor. A capacidade, por parte dos indivíduos racionais, de antecipar as ações, de extrair suas conseqüências e avaliá-las em termos de seus custos e benefícios permite que cada um dos indivíduos primeiramente identifique ser o direito natural de se auto-preservar o elemento central que faz do modelo do Estado de Natureza um Estado de Guerra. Em segundo lugar, permite, também, a partir da razão e do conhecimento da natureza humana, construir uma solução que é uma tecnologia capaz de promover esse interesse comum: a segurança coletiva. Essa tecnologia é construída para realizar uma função como se fosse uma máquina que deve extrair água de poços profundos, ou como se fosse uma lente que deve corrigir seja a miopia seja o astigmatismo. O estudo das leis da ótica e do olho humano permite construir a tecnologia adequada para resolver o problema da miopia. Do mesmo modo, o estudo da natureza e da ação humana e do modelo formado por indivíduos interagentes - que tem a natureza de um modelo de Estado de Guerra, em que todos estão em guerra com todos - permite conceber uma tecnologia para proporcionar a cooperação entre esses indivíduos interagentes. Essa tecnologia é o modelo do Estado Civil capaz de realizar a tarefa de garantir a preservação da vida para cada um dos seus membros por tanto tempo quanto sua constituição natural permita, portanto, que os indivíduos tenham segurança para morrer de morte natural e não de morte violenta.

Esse estudo mostra não ser viável fazer surgir espontaneamente o interesse comum pela segurança a partir de indivíduos auto-interessados ${ }^{3}$. Mostra que não é possível que a liberdade natural permita fazer surgir espontaneamente a cooperação e convivência social. Trata-se de elaborar um mecanismo que permita fazer convergir os interesses, produzindo uma ação coletiva capaz de cumprir o objetivo de garantir, simultaneamente, o direito à vida de todos os indivíduos e que possibilite a cooperação multilateral relativa a esse fim, evitando, assim, o problema do free-rider. Hobbes tem, portanto, consciência de que seu problema é aquele de uma teoria da ação coletiva: como é possível uma ação coletiva a partir das ações privadas? Como é possível transformar os interesses privados em interesse comum? A resposta encontra-se no modo como ele construiu os dois conjuntos de dados que definem o problema (LEISTER, 2005). Os dois conjuntos de dados referem-se ao domínio das relações privadas nas quais os indivíduos conduzem suas relações pes-

\footnotetext{
3 Os teóricos modernos que fazem uso da teoria dos jogos para interpretar a problemática hobbesiana têm quebrado a cabeça para justificar porque, supondo que no Estado de Natureza se desenvolve um jogo iterado a cooperação não emerge naturalmente dessa interação entre indivíduos, ainda sendo eles auto-interessados. A estratégia mais comumente adotada da parte desses teóricos é introduzir algum incentivo extra para inviabilizar a cooperação natural. Hampton, por exemplo, a tese da miopia, segundo a qual nem todo indivíduo dispõe de racionalidade perfeita para perceber a vantagem da cooperação espontânea. Por conta desses indivíduos miopes, e porque os demais indivíduos não conseguem identificar previamente quando estão diante de outro indivíduo totalmente racional ou míope, a informação imperfeita surge como incentivo capaz de justificar a não emergência da cooperação, dado o Estado de Natureza hobbesiano.
} 
soais, familiares e comerciais, sempre conduzidos pelo princípio da autonomia da vontade. As relações entre os particulares são efetivadas por meio do instrumento do contrato. Com esse instrumento, eles trocam seus direitos de propriedade e assumem obrigações. Se os indivíduos são racionais, eles entram em relações contratuais apenas e somente se podem realizar vantagens mútuas, mas, como os indivíduos estão submetidos às paixões e não tem informação perfeita, não há garantia de que esse contrato garanta o interesse comum.

Como o contrato envolve também decisões intertemporais, e decisões intertemporais envolvem a incerteza em relação ao futuro, não há garantia de que as obrigações serão cumpridas. Como fazer para garantir que as obrigações assumidas sejam cumpridas e tornar o contrato um instrumento tecnológico capaz de viabilizar as relações entre particulares? Firmando um contrato social entre todos os indivíduos, em que eles trocam seu direito natural individual - de recorrer a todos os recursos para resolver seus conflitos - por uma segurança coletiva. Essa tecnologia é o contrato que faz com que: i) cada indivíduo expresse sua promessa de transferir o seu direito natural; ii) seja criado um árbitro, o Soberano, receptor dessa alienação do direito natural de cada indivíduo e dotado de um aparato de poder coercitivo absoluto para garantir que as promessas serão cumpridas por meio de um sistema de regras, um sistema judicial, organizando suas interações e cuja quebra será punida com sanções suficientemente fortes para que não haja incentivo a novas violações. A ciência da natureza humana produz, assim, um contrato para realizar a norma, expressando uma tecnologia que afirma o seguinte comportamento: se queres $\mathrm{Y}$, deve $\mathrm{X}$, ou seja, se queres segurança, cumpra o contrato de transferência do direto natural para um árbitro, o Estado Civil, construído com poderes absolutos especialmente para velar por esse cumprimento e garantir o direito à vida de cada indivíduo.

$\mathrm{O}$ estudo da natureza humana ensina-nos que devemos construir um mecanismo para garantir nosso direito à vida. Esse mecanismo é o Estado Civil, que é, portanto, o resultado de uma decisão dos indivíduos e, como tal, uma convenção artificial decorrente dos poderes racionais dos indivíduos que buscam na ciência os meios para realizar seu bem-estar, que começa pela garantia de seu direito à vida. Artificial porque se trata de um instrumento ou tecnologia construída como resultado de um planejamento guiado pela ciência da natureza humana na tentativa de resolver os problemas da interação entre os indivíduos. Podese notar que a relação entre o modelo do Estado de Natureza como Estado de Guerra e o modelo do Estado Civil é mediada por uma idéia intermediária que é o contrato. $\mathrm{O}$ contrato tem a forma de uma norma técnica semelhante ao princípio da causalidade. $\mathrm{O}$ princípio da causalidade funciona também como uma idéia intermediária entre a causa e o efeito no caso do modelo cartesiano das condições de possibilidade do conhecimento. Descartes alcança a primeira e a segunda verdades, que são a existência e a natureza do cogito como uma coisa pensante, mas com um indivíduo que só existe, como pensante, enquanto pensar na sentença "eu sou, eu existo". Não há garantia de sua existência fora dessa possibilidade. Para garantir a prova da existência objetiva do indivíduo, Descartes mostra que é preciso provar que Deus existe e que é seu criador. Ele faz isso por meio do principio da causa e efeito, que é aplicado ao estudo de suas diversas idéias na procura por uma que a natureza substancial do cogito não poderia ter criado: é o que acontece com a idéia de Deus. Se há a idéia de Deus é porque ele é a causa desta idéia em nós. O princípio da causalidade é a medida, a idéia intermediária, entre o indivíduo e Deus. Com isso, Descartes mostra que se trata de um mesmo ato a compreensão de sua existência e aquela da existência de Deus.

Não é outra coisa o que acontece com a abordagem de Hobbes. A existência das interações entre os indivíduos, por meio da tecnologia do contrato, é ao mesmo tempo a compreensão da existência do Estado Civil como garantia dessas relações contratuais. A construção das relações contratuais entre os indivíduos é simultânea à construção do Estado Civil como garantia dessas relações contratuais. O modelo utilizado por Hobbes para a construção da Política e do Direito como ciência segue o modelo cartesiano da Mathesis Universalis: estabelecer ordem e medida na organização do conhecimento. Podemos ver claramente, na abordagem de Descartes nas $\mathrm{Me}$ ditações, que o princípio da causalidade é a medida que estabelece a ordem entre o cogito e a existência de Deus, enquanto, no Leviatã (HOBBES, 1974), o contrato é a medida que estabelece a relação ordenada entre o modelo do Estado de Natureza, como Estado de Guerra, e o modelo do 
Estado Civil, como um estado de paz e garantia das relações contratuais. A tese a ser fundamentada por Hobbes é de que deve haver, nesta passagem do Estado de Natureza para o Estado Civil, uma troca entre liberdade natural, igualdade natural e o direito à vida ou direito à morte natural.

Segundo Hobbes, os bens jurídicos podem ser trocados, assim como quaisquer bens materiais. Essa troca é feita segundo a análise de custo e benefício por cada um dos indivíduos. O benefício da garantia ao direito à vida é feito com o custo da construção do Estado Civil, ou seja, com o custo de diminuir a extensão do domínio das relações privadas, com o estabelecimento da liberdade civil, que é a liberdade segundo leis, para a criação de uma esfera das relações públicas. Há também o custo da perda da igualdade pelo estabelecimento da relação hierárquica entre o Estado Civil e o indivíduo, segundo o princípio da supremacia do interesse público. No entanto, o custo de se permanecer no Estado de Natureza, como Estado de Guerra, é aquele da própria vida, ou seja, é infinito. Esse modelo vai ser também seguido, com ajustes, pelos demais membros do programa contratualista. A tese a ser defendida por Locke figura, contudo, como uma troca entre liberdade e desigualdade, esta última naturalmente obtida, sendo instituída por meio do direito à propriedade, que lhe é atribuída pelo trabalho $\mathrm{e}$ pela não ingerência por parte do Estado Civil nesses direitos (LEISTER \& CHIAPPIN, 2007c) ${ }^{4}$.

O Estado de Natureza é transformado em Estado de Guerra, em Locke, por conta do caráter subjetivo atribuído à imputação da pena, caso as leis naturais sejam violadas. Ou seja, em Locke, subsiste um poder legislativo natural, com a natureza e a lei natural derivadas como um teorema da razão, mas não como um poder natural na aplicação da pena aos transgressores dessa lei natural. Desta forma, a punição, que deveria operar como mecanismo de estabilização da interação humana no Estado de Natureza, termina por engendrar a instabilidade nessas relações, visto que a aplicação da pena contraria o princípio da proporcionalidade entre o delito e sua pena correspondente. É em função dessa desproporção que o Estado de Natureza lockeano decai em Estado

\footnotetext{
4 Ou seja, em Locke, a igualdade natural inicial é rapidamente substituída pela desigualdade, obtida ainda no Estado de Natureza.
}

de Guerra. Diversamente, o método de construção do problema, em Rousseau, traz componentes novos à tradição contratualista, consistindo ainda no recurso aos modelos mencionados anteriormente, mas desenvolvidos de forma muito mais dinâmica do que os teóricos anteriores fizeram e dando origem a uma espécie de história racional, ao estilo dos modelos de Descartes sobre a origem do sistema solar, que foram construídos com o uso das leis mecânicas, portanto, uma história racional do universo, que vai dar origem ao modelo dinâmico e teleológico de Kant e ao modelo teleológico de vários autores do século XIX. Por outro lado, podemos dar destaque, também, ao método de construção de Kant, que pode ser denominado de método do "princípio da autonomia", pelo fato de que Rawls o tem como um modelo para o seu método da "Posição Original", com o qual justifica e pretende legitimar os dois princípios da justiça.

\section{O MÉTODO CONTRATUALISTA: CON- TRATUALISMO RAWLSIANO}

O método contratualista rawlsiano é constituído em analogia ao método contratualista clássico. Este, por sua vez, está associado aos métodos de Galileu e Descartes. Neste método, hipostasiado na "Posição Original", o objetivo é fornecer um procedimento capaz de acessar fundamentos que, em Rawls, são seus dois princípios de justiça. Mas Rawls, ao incorporar o método cartesiano, verifica que este é, sozinho, suficiente para acessar fundamentos, tornando as idéias inatas irrelevantes. Igualmente desnecessário figura o jusnaturalismo dos contratualistas, daí o fundacionismo rawlsiano dispensar certo apriorismo daqueles (apriorismo que, acreditamos, com nosso argumento acerca do contratualismo como método, poderia mesmo ser dispensado nos clássicos). Esse posicionamento é expresso, por exemplo, na seguinte passagem, na qual Rawls reinterpreta o contratualismo: "As razões para essa confiança, segundo o entendimento contratualista, estão no fato de que as liberdades têm um fundamento completamente diferente. [...]. Em vez disso, esses direitos são atribuídos para satisfazer os princípios de cooperação que os cidadãos reconheceriam quando cada um estivesse representado de forma justa como uma pessoa ética" (RAWLS, 2002, p. 229).

Para Rawls, a cooperação é devida à aceitação consensual de um sistema de regras encabeçado por seus dois princípios de justiça, o princípio da 
maior liberdade igual e o princípio da diferença, operacionalizados por meio de certa ordenação lexical, o primeiro precedendo o segundo. Esses dois princípios são, portanto, o fundamento ou ponto fixo de Arquimedes, como em Descartes, e obtidos por meio de sua metodologia contratualista, a qual adota a "Posição Original" e o "Véu da Ignorância" como construções auxiliares para acessar esses dois princípios, assumindo, contudo, de antemão, que seu indivíduo é avesso ao risco, daí adotar o princípio maximin como meta-regra para a escolha desses dois princípios como seus princípios de justiça. Por meio desse método, os únicos incentivos que subsistem e que, portanto, podem ser sustentados como pertencendo à natureza humana, para além de sua aversão a risco (aversão esta também sustentada por Hobbes), é um senso de justiça, o que indica que o indivíduo rawlsiano é um agente moral. Desse procedimento, que anula toda a subjetividade do auto-interesse, é que podem ser acessados e aceitos os dois princípios de justiça, ambos interpretando justiça como eqüidade. Rawls explicita o método contratualista: "A definição contratualista vai mais além: tenta fornecer uma base dedutiva para os princípios que explicam esses julgamentos. Pretende-se que as condições da situação inicial e a motivação das partes formulem as premissas necessárias para que se atinja esse objetivo" (idem, p. 202).

$\mathrm{Na}$ interpretação da justiça como eqüidade, o surgimento da cooperação justifica-se não em função dessa associação incorrer em ganhos mútuos, embora eles sejam admitidos, mas porque os frutos dessa associação são justamente distribuídos. Assim sendo, em Rawls, assim como nos contratualistas clássicos, o contratualismo é adotado como procedimento para acessar fundamentos ou, na terminologia de Descartes - retomada por Rawls -, para encontrar seu ponto fixo de Arquimedes. Contudo, a discussão envolvendo as diferenças entre o contratualismo como método, em Rawls e nos modernos, de um lado, e nos clássicos, de outro, bem como a diferente matriz epistemológica adotada pelo contratualismo clássico e moderno será objeto de um próximo artigo nosso. O objetivo buscado neste texto foi o de mostrar que muitos dos métodos utilizados na política do século XVII decorrem de um intercâmbio com a ciência da época. Enquanto Hobbes fazia uso dos métodos e modelos de Galileu e de Descartes, na Física e na Geometria, Rawls faz o mesmo contemporaneamente buscando novos métodos e modelos na Economia, como a ciência social mais avançada de sua época. Rawls segue epistemologicamente uma concepção de ciência próxima do racionalismo crítico de Popper, enquanto, do ponto de vista metodológico, ele busca seus recursos na microeconomia, em particular no modelo de equilíbrio geral como aquele capaz de proporcionar o seu ponto fixo teórico. A ironia é que a metáfora de Descartes de um ponto fixo era de fato uma metáfora, mas, no caso do modelo de equilíbrio geral é muito mais do que isso, pois o fundamento do modelo do equilíbrio geral é o teorema do ponto fixo. É por meio desse aparato contratualista que Rawls pretende opor-se às propostas dos utilitaristas clássicos e modernos.

\section{CONCLUSÕES}

$\mathrm{O}$ artigo mostra que o programa contratualista clássico é praticamente uma metodologia de solução de problemas, uma aplicação da matriz epistemológica do racionalismo clássico de Galileu e Descartes, por meio da qual se pretendeu transformar a Política e o Direito em ciência. A metodologia contratualista recorre, assim, aos métodos científicos da época: i) recorreu ao modelo geométrico como forma de organizar o conhecimento; e ii) ao modelo atomista mecânico da natureza, como indutor da pressuposição de que a única entidade existente é o indivíduo racional e auto-interessado.

O objetivo dos contratualistas foi o de explicar todos os demais fenômenos a partir desta pressuposição ontológica. O problema concreto do contratualismo era o de como explicar o Estado Civil e sua natureza se o que existe são os indivíduos racionais e auto-interessados, ou, ainda, de por que existe o Estado Civil e não apenas a liberdade natural guiada pelo princípio da autonomia da vontade. Para responder a isso, recorreram à teoria do movimento de Galileu, a fim de construir a teoria da ação humana. Recorreram, principalmente, aos experimentos mentais para construir e legitimar as leis fundamentais que dariam autonomia à política. Recorreram, também, como fundamental, ao método analítico, com Galileu e Descartes, para resolver os problemas dos interesses comuns formados a partir do auto-interesse individual. Essa análise do método contratualista é uma ponte para se estudar a proposta de Rawls de reconstruir o contratualismo em oposição ao utilitarismo, mas agora com os recursos de novos métodos, como aqueles da Economia. 
J. R. N. Chiappin (chiappin@usp.br) é Doutor em Economia pela Universidade de São Paulo (USP) e Professor na mesma instituição.

Carolina Leister (carolina.leister@fgv.br) é Doutora em Filosofia pela Universidade de São Paulo (USP) e Professora na Fundação Getúlio Vargas (FGV).

\section{REFERÊNCIAS BIBLIOGRÁFICAS}

BENTHAM, J. 1843. The Works of Jeremy Bentham, vol. 1 (Principles of Morals and Legislation, Fragment on Government, Civil Code, Penal Law). Edinburgh: William Tait. Disponível em : http://oll.libertyfund.org/ index.php? option $=$ com_staticxt\&staticfile $=$ show.php $\% 3$ Ftitle $=2009 \&$ Itemid $=27$. Acesso em 1.dez.2009.

CHIAPPIN, J.R.N. 1996. Racionalidade, Decisão, Solução de Problemas e o Programa Racionalista. Ciência \& Filosofia, São Paulo, n. 5 , p. $155-219$.

CHIAPPIN, J.R.N. \& OLIVEIRA, J. M. 1999. The Emergence of Cooperation Among Interacting Individuals. Physical Review E, College Park, v. 59, n. 6, p. 6419-6421.

DESCARTES, R. 1967. Oeucres philosophiques. Tome II. Paris: Garnier Préres

1971. Regras para a Direção do Espírito. Lisboa : Estampa.

HOBBES. T. 1974. Leviatã. In : Os Pensadores. São Paulo: Abril.

KOYRÉ, A. 1966. Études Galiléennes. Paris : Hermann.

LAKATOS, I. 1979. O falseamento e a metodologia dos programas de pesquisa científica. In : LAKATOS, I. \& MUSGRAVE, A. (orgs). A crítica e o desenvolvimento do conhecimento. São Paulo : USP.

LEISTER, C. 2005. Social Choice e Public Choice: o problema da agregação e o cálculo das regras de decisão coletiva como fórmulas de alocação/distribuição de recursos. São Paulo. Tese (Doutorado em Filosofia). Universidade de São Paulo.

LEISTER, C. \& CHIAPPIN, J.R.N. 2007a. $O$ Programa de Pesquisa sobre a Politica e o Direito como Ciência e o Problema das Condições de Emergência e Estabilidade da Cooperação entre Indivíduos Interagentes : A Construção do Estado De Direito e o Núcleo Teórico do Contratualismo. No prelo.

2007b. O programa de pesquisa sobre a Política e o Direito como ciência e o problema das condições de emergência e estabilidade da cooperação entre indivíduos interagentes : a construção do Estado de Direito e a heurística do contratualismo. No prelo.

2007c. Experimento Mental I : A Concepção Contratualista Clássica, O Modelo da Tragédia dos Comuns e as Condições de Emergência da Cooperação. Locke, Rousseau e Kant. Annual Papers, Berkeley, Berkeley Program in Law \& Economics, Latin American and Caribbean Law and Economics Association (ALACDE), paper 060507-1.

LOCKE, J. 1973. Os Pensadores. São Paulo : Abril.

RAWLS, J. 2002. Uma Teoria da Justiça. São Paulo : Martins Fontes.

WIEACKER, F. 1967. História do Direito Privado moderno. Lisboa : Fundação Calouste Gulbenkian. 


\section{ABSTRACTS}

\section{CONTRACTUALISM AS A METHOD: POLITICS, LAW AND NEO-CONTRACTUALISM}

\section{José R. N. Chiappin and Carolina Leister}

The goal of this article is to present contractualism as a method and as a result of the systematizing of other methods for constructing knowledge. While classical contractualism takes its paradigms from the geometric and mechanical models of Galileo's physics and from Descartes - particularly, the latter's model of rational choice - Rawlsian contractualism takes its paradigm from several micro-economic paradigms, and that of general equilibrium in particular. The contractualist method of the $17^{\text {th }}$ Century has making politics and Law into a scientific discipline as its project, considering that, during this epoch: (i) the prevailing model of knowledge is the geometric one and knowledge is definite knowledge; (ii) the prevailing model of the individual sees the latter as rational and moved by self-interest; (iii) it entails a theory of rational human action and decision-making. Therefore, in order to make the project of turning politics and Law into science more viable, contractualism is not interpreted here substantively but instrumentally, as a method to access the bases of the political world. The contractualist method pursues a combination of the scientific model of knowledge of efficient causes and their relationship with effects, with the model of knowledge of ultimate causes as the study of ends or of the functional characteristics of things. In order to interpret contractualism as a method, we accept the new model of the relationship between knowledge and technology that has been elaborated by modern science and which maintains that knowledge of nature is a knowledge of conquest and domination that is capable of producing technological mechanisms for intervening in nature, with the goal of uncovering and manipulating causes in order to obtain the desired effects. .

KEYWORDS: classical contractualist method; politics and Law as science; geometric model; rational choice model; problem solving method. 


\section{LE CONTRATUALisme COMME MÉthode: POLITIQUE, DROIT ET NÉOCONTRATUALISME}

\section{José R. N. Chiappin et Carolina Leister}

L'objectif de cet article est de présenter le contractualisme comme une méthode et le résultat d'une systématisation des autres méthodes de construction des savoirs. Alors que contractualisme classique possède comme paradigmes les modèles, géométrique et mécanique, de la physique géométrique de Galilée et Descartes - en particulier, le modèle du choix rationnel avec Descartes - le contractualisme de Rawls a comme paradigme certains modèles de la micro-économie - en particulier, le modèle d'équilibre général. La méthode contratualiste envisage de transformer, au XVIIe siècle, la politique et le droit en discipline scientifique, à supposer que, au XVIIe siècle : (i) le modèle de la connaissance est le modèle géométrique et la connaissance est la connaissance correcte ; (ii) le modèle reconnaît l'individu comme rationnel et auto-intéressé, (iii) il existe une théorie rationnelle de l'action et de décision humaine. Par conséquent, pour permettre à ce projet de transformer la politique et de droit en science, le contractualisme est ici interprété non pas sur le fond, mais comme instrument, comme une méthode pour accéder aux fondements du monde politique.La méthode contractualiste poursuit une combinaison du modèle scientifique de la connaissance des causes efficientes et leurs effets sur les relations avec le modèle de connaissance des causes finales et comme éetudes des fins ou des caractéristiques fonctionnelles des choses. Pour interpréter le contractualisme comme une méthode, nous acceptons le nouveau modèle de relation entre les connaissances et la technologie développé par la science moderne, qui prétend que la connaissance de la nature est la connaissance de la conquête et de la maîtrise à son tour capable de produire des mécanismes technologiques d'intervention dans la nature afin d'obtenir les effets souhaités tout en connaissant et manipulant les causes.

MOTS-CLÉS : méthode contractualiste classique ; politique et droit comme science ; modèle géométrique ; modèle du choix rationnel; méthode de solution de problèmes. 